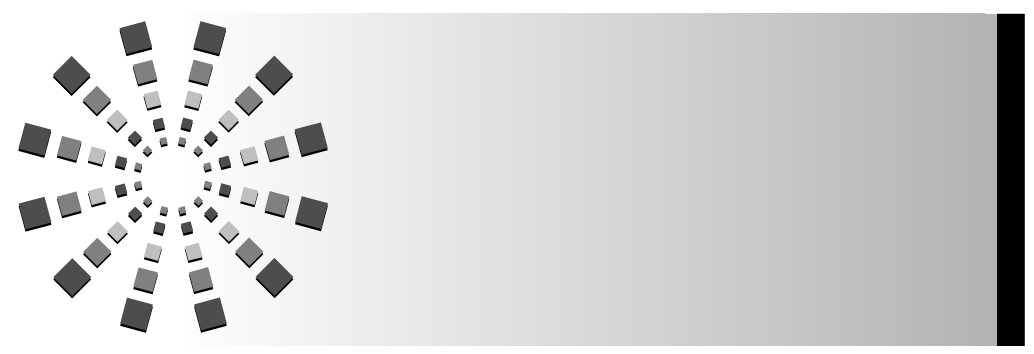

Maryam Khazaee-Pool, PhD

Tahereh Pashaei, PhD

Rashin Alizadeh, PhD

Koen Ponnet, PhD

\title{
New Educational Model to Promote Breast Cancer-Preventive Behaviors (ASSISTS)
}

\section{Development and First Evaluation}

\section{$\begin{array}{llllllll}K & E & Y & \text { W } & \text { O } & R & \text { D } & S\end{array}$}

Breast cancer

Educational model

Preventive behaviors

Women
Background: The prevalence of breast cancer in Iran has increased. An effective approach to decrease the burden of breast cancer is prevention. Objective: The aim of this study was to develop and evaluate an educational model, called the ASSISTS, for promoting breast cancer-preventive behaviors in women. Methods: A multiphase method was used to develop the model designed to promote breast cancer prevention behaviors. A conceptual model was generated based on a secondary analysis of qualitative data. Then, a structural equation model technique was used to test the relationships among the model constructs. Results: The analysis revealed that 7 constructs could be extracted, namely, perceived social support, attitude, motivation, self-efficacy, information seeking, stress management, and self-care. Based on these constructs, a conceptual model was built and tested using structural equation modeling. The model fit was good, and the model confirmed significant relationships among the 7 constructs of breast cancer prevention. Conclusion: Findings revealed that self-care behavior and stress management are influenced directly by attitude, motivation, self-efficacy, information seeking, and social support. In addition, women seek more information when they are motivated, have more self-efficacy, have a more positive attitude toward breast cancer prevention, and experience more social support.

Implication for Practice: Cancer nurses can be at the forefront of breast cancer prevention. Because they can play a pivotal role in providing information, they can
Author Affiliations: Department of Health Education and Promotion, School of Public Health, Zanjan University of Medical Sciences (Dr Khazaee-Pool), Zanjan; Environmental Health Research Center, Kurdistan University of Medical Sciences (Dr Pashaei); Social Determinants of Health Research Center, Kurdistan University of Medical Sciences (Dr Pashaei); Department of Public Health, Faculty of Health, Kurdistan University of Medical Sciences (Dr Pashaei), Sanandaj, Iran; Department of Health Education and Promotion, School of Health, Tehran University of Medical Sciences (Dr Alizadeh), Iran; Department of Communication Studies, Research Group for Media \& ICT (MICT-IMEC), Ghent University (Dr Ponnet); and Department of Communication Studies,
Media, ICT/Interpersonal Relations in Organizations and Society (MIOS), University of Antwerp (Dr Ponnet), Belgium.

Funding for this study was provided by Tehran University of Medical Sciences (grant number 20055).

The authors have no conflicts of interest to disclose.

Correspondence: Maryam Khazaee-Pool, PhD, Department of Health Education \& Promotion, School of Public Health, Zanjan University of Medical Science, Parvin Etesami St, P.O. Box: 451578-6349, Zanjan, Iran (khazaee.m@zums.ac.ir).

Accepted for publication August 30, 2017.

DOI: $10.1097 /$ NCC.0000000000000560 
reduce women's stress and increase their self-care behavior. In addition, their social support can positively influence Iranian women's attitude, motivation, and self-care behavior. Furthermore, implementing educational programs based on this model might encourage women to practice preventive behaviors.

$\mathrm{B}$ reast cancer is an important health concern in developed and developing countries. ${ }^{1}$ It is the most common type of cancer, with a negative impact on both the women's longevity and quality of life and is a leading cause of cancer death among women around the world. ${ }^{2}$ The incidence of breast cancer has increased in the previous decades because of variations in the prevalence of fertility risk factors, lifestyle changes, and genetic elements. ${ }^{3}$ Furthermore, increasing life expectancy contributes to the growing breast cancer incidence. Developed countries have a higher incidence of breast cancer than developing countries. Mortality has declined throughout the previous 4 decades because of improvements in treatment approaches and screening behaviors. ${ }^{4}$ Although early detection and treatment of breast cancer have decreased its mortality, the real challenge is to decrease breast cancer incidence. Several breast cancer risk factors can be allocated into changeable and nonchangeable elements. There is a possibility for decreasing breast cancer incidence by altering the changeable risk factors, such as nutritional modifications or modifications to a sedentary lifestyle. A decrease in breast cancer incidence by focusing on nonchangeable risk factors, such as genetic factors, may, however, require other methods. ${ }^{5}$ Several studies conducted in Iran have shown that breast cancer is a leading cause of death among the top 5 most common cancers and is the most frequent cancer detected in Iranian women. Breast cancer affects Iranian women almost 1 decade earlier than women in the developed world. ${ }^{6}$ The incidence rate of breast cancer in Iranian women is $24.6 \%$ of all cancers, and $67.6 \%$ of the affected women are between 35 and 60 years of age. ${ }^{7}$

Several risk factors increase the probability of breast cancer, but behavioral factors - such as a low level of exercise, unhealthy eating habits, smoking, drinking alcohol, and a high level of stress - might have a key role in the risk of developing breast cancer. ${ }^{8,9}$ These behavioral factors are both important risk factors for developing breast cancer and may influence individuals' health outcomes and well-being. ${ }^{10}$ Therefore, prevention practices can decrease the burden of breast cancer and its associated mortality. Screening behaviors, such as clinical breast examinations or breast self-examinations, together with improvements in lifestyle habits, such as quitting smoking, eating more healthily, increasing physical activity, and learning to control one's stress levels, may contribute to early detection of breast cancer and, thereby, reduce the risk of mortality. ${ }^{11}$ However, because only a few Iranian women report performing breast cancer screening, focusing on the improvement of healthy lifestyles might be important to develop positive healthcare practices and improve health outcomes. ${ }^{8}$

It is important to advance the future health of today's people by applying health promotion interventions. The necessity for health promotion may be even more important for persons whose quality of life independently, and often seriously, depends on keeping their health, which may be considerably affected by cancer. Preventing behavior from an early age (ie, in childhood) is an approach that will obtain health benefits in the long run. Population-based prevention approaches aim to modify the habits of individuals by encouraging an increase in healthy behaviors and a decrease in health-threatening behaviors. Changing one's lifestyle is not, however, easy, and there is evidence that interventions are more effective if they are based on a theory or a conceptual model. ${ }^{12,13}$ Effective population-based prevention depends on applying educational models. ${ }^{14,15}$ In addressing this issue, there is an urgent need to develop an effective educational model that is able to identify the various dimensions of breast cancer-preventive behaviors. Well-defined dimensions of behaviors that increase individuals' self-care and healthy lifestyles are vital to prevent women from developing breast cancer.

Several studies have been conducted to develop effective strategies that might increase the Iranian women's knowledge of breast cancer screening, breast self-examination, and clinical breast examination. ${ }^{15-17}$ However, to the best of our knowledge, no study has developed and evaluated a conceptual model for factors associated with breast cancer-preventive behaviors to increase these behaviors in the community of Iranian women who are in the age group at risk for breast cancer. The aim of this study was to develop an educational model, called the ASSISTS, for promoting breast cancer-preventive behaviors among Iranian women and to evaluate this model by means of structural equation modeling (SEM). A multiphase method was applied; we developed a conceptual model based on a secondary analysis of previously gathered qualitative data, ${ }^{18}$ and then we conducted a cross-sectional study among 260 Iranian women and tested our conceptual model.

\section{Methods}

\section{Phase 1: Development of Our Conceptual Model}

We first developed a conceptual model that consisted of constructs with subthemes that influence women's breast cancerpreventive behaviors. Constructs and indicators were derived based on secondary analysis of qualitative research published in 2014 by Khazaee-Pool and colleagues, ${ }^{11}$ in which Iranian women's experiences with breast cancer-preventive behaviors were explored. Based on this secondary analysis, 7 key themes were found, including (1) attitudes, (2) self-efficacy, (3) motivation, (4) self-care, (5) perceived social support, (6) information seeking, and (7) stress management. The model with the key themes and subthemes is presented in Table 1. Based on the themes, a conceptual model was generated. The model was called ASSISTS based on one the letter of each seven subscales including A: attitudes, S: support systems, S: self-efficacy, I: information seeking, S: stress management, T: motivation, and $S$ self-care (Figure 1). 


$\begin{aligned} & 3: \text { Table } 1 \text { Themes and Subthemes Identified by } \\ & \text { Secondary Analysis of Previous } \\ & \text { Data (Phase 1) }\end{aligned}$

Themes Subthemes

Attitudes toward breast cancer and prevention

$\begin{array}{ll} & \text { Self-esteem } \\ \text { Self-responsibility } \\ \text { Motivation for changing behavior }\end{array}$

Motivation

Self-care

Stress management

$\begin{array}{ll} & \text { Positive Thinking } \\ & \text { Relaxation } \\ & \text { Spirituality }\end{array}$

Social support

Information seeking

\section{Family and friends support}

Healthcare system support

Support from government and policy makers

Insufficient family support

Lack of resources and facilities

Weaknesses of strategies and policies

\section{Media}

Public education

Intersectional cooperation

Interpersonal interactions

Inattention to individual needs

Stereotypical training

Insufficient informing

\section{Phase 2: Empirical Section}

In a second phase, we investigated the relationship between the 7 themes of the previously mentioned conceptual model in a sample of 260 women by means of SEM.

All women received oral and written information about the study and their tasks before the beginning of the project. Written consent forms were signed by all the women, who were informed that they were free to leave the study at any time they wanted. The study was approved by the regional ethical committee (registration code at Registry Center Clinical Trial of Iran: IRCT201305068742N2).

Based on the theoretical and empirical knowledge of the 7 themes, the following hypotheses were formulated: (a) perceived social support is positively associated with self-efficacy, ${ }^{19}$ motivation, ${ }^{20}$ and attitude, ${ }^{21}$ which in turn is positively associated with information seeking, self-care, and stress management ${ }^{22-25} ;(b)$ social support is positively associated with information seeking, ${ }^{26}$ self-care, ${ }^{27}$ and stress management ${ }^{28}$; and $(c)$ information seeking is positively associated with self-care and stress management ${ }^{29,30}$ (Figure 1).

\section{PARTICIPANTS AND DATA COLLECTION}

A total of 260 healthy women aged 30 to 75 years with different educational levels and employment statuses were included in the analysis. The subjects enrolled in the study through healthcare centers affiliated with Tehran University of Medical Sciences, Iran. The women received a courtesy gift (ie, a pool ticket) and were thanked for participating. Women signed a consent form, in which the following inclusion criteria were mentioned: $(a)$ participants had to be healthy (ie, without a history of breast cancer) and (b) they had to be literate. Descriptive characteristics of the sample are shown in Table 2. The sociodemographic characteristics of the 260 participants revealed a mean age of $45.12 \pm 5.92$ years. Most participants were married $(56.54 \%)$ and had some college or higher education (58.08\%). More than half of the participants were employed (55\%).

\section{MEASURE: ASSISTS SCALE}

The relationships between the 7 themes were examined using the ASSISTS, which is a 33-item self-report scale designed to measure factors affecting breast cancer-preventive behaviors in

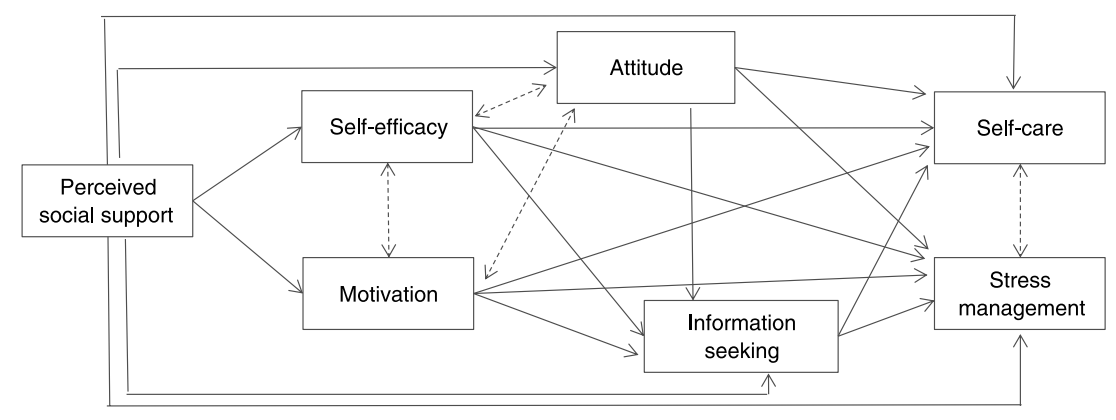

Note. Dashed lines represent interrelationships

Figure 1 Conceptual model. 
Table 2 - Sample Sociodemographic Characteristics $(\mathrm{N}=260)$

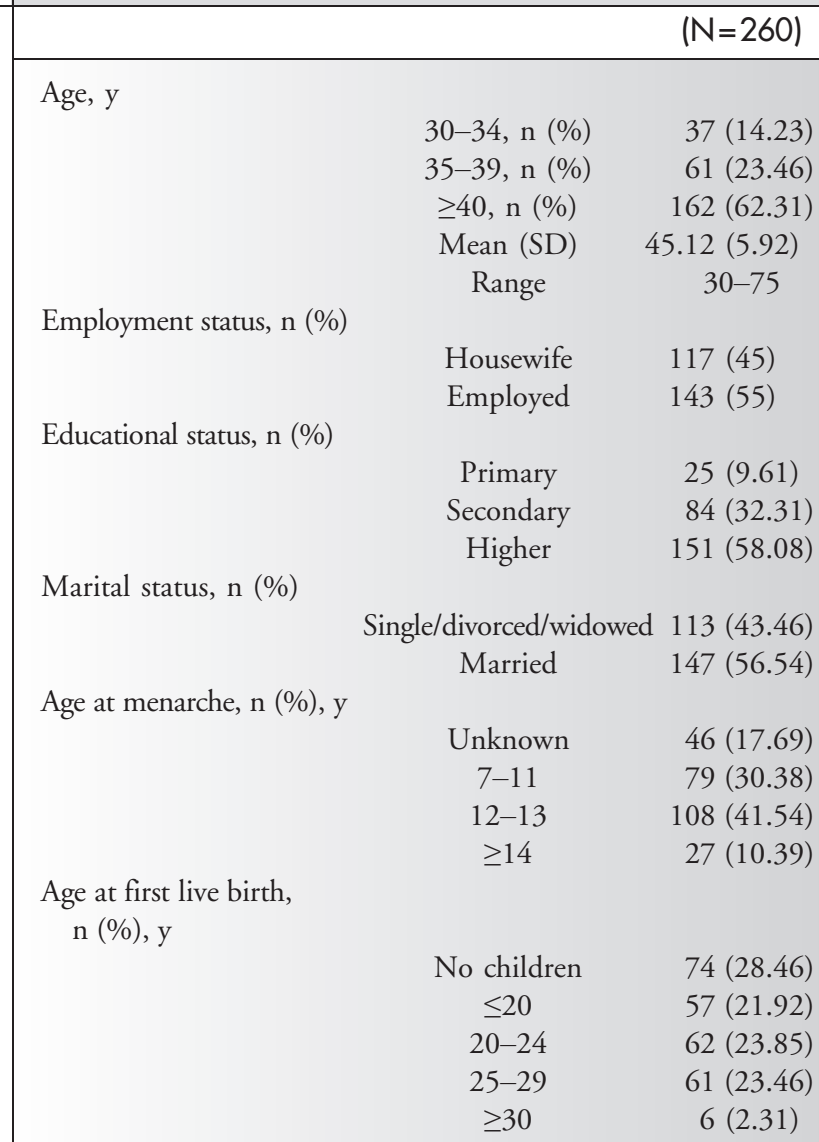

Number of first-degree relatives with breast cancer, n (\%)

0

1

$>1$

$194(74.61)$

$49(18.85)$

17 (6.54)

Biopsy, n (\%)

No

Yes (1 biopsy)

$257(98.85)$

Yes ( $>1$ biopsy)

$3(1.15)$

Living a breast

problems, n (\%)

$\begin{array}{cc}\text { No } & 251(96.54) \\ \text { Neoplasm } & 0(0) \\ \text { Cyst } & 9(3.46)\end{array}$

Breast cancer screening, n (\%)

$$
\begin{gathered}
\text { Mammography } \\
\text { Sonography } \\
\text { No }
\end{gathered}
$$

women. ${ }^{31}$ The ASSISTS scale comprises 7 subscales: supportive systems ( 5 items, Cronbach's $\alpha=.85$ ), efficacy (3 items, Cronbach's $\alpha=.83$ ), self-care (7 items, Cronbach's $\alpha=.82$ ), stress management (3 items, Cronbach's $\alpha=.81$ ), motivation (3 items, Cronbach's $\alpha=.79$ ), information seeking ( 4 items, Cronbach's $\alpha=.79$ ), and attitude ( 8 items, Cronbach's $\alpha=.69$ ). Sample items include "My health is OK, which is why I do not think at all that sometime I might develop breast cancer" (attitude, reverse scored), "I am able to make decisions about routine mammograms in order to maintain my breast health" (self-efficacy), "My family members pay attention and give me good advice about breast cancer prevention" (supportive systems), and "I try to avoid negative thoughts about breast cancer even if I am afraid that I may have cancer" (stress management). Each item was rated on a 5-point Likert-type scale ranging from 1 (never) to 5 (always). Possible scores ranged from 33 to 165, with higher scores indicating more favorable breast cancer-preventive behaviors. The ASSISTS questionnaire has been used with native Iranian women and has demonstrated robust psychometric properties. ${ }^{31}$

\section{ANALYTIC STRATEGY}

Our analyses began with a discussion of the intercorrelations among the study variables. Then, we built a measurement model and investigated the fit. Thereafter, we conducted a structural equation to examine the associations between the study variables. The model fit for the measurement and structural model was assessed using the $\chi^{2}$ difference test, with a $P$ greater than .05 indicating a good $\mathrm{fit}^{32}$; root mean square error of approximation (RMSEA) and the standardized root mean square residual (SRMR) with values less than 0.05 indicated a good fit and values between 0.05 and 0.08 indicated an adequate fit. ${ }^{33}$ The goodness-of-fit index (GFI) and the normed fit index (NFI) were examined, with values above .95 indicating a good fit and values between .90 and .95 indicating an acceptable fit. Furthermore, the comparative fit index (CFI), Tucker Lewis fit index (TLI), and the non-normed fit index (NNFI) were examined, with values higher than 0.95 indicating an acceptable fit and values higher than 0.97 indicating a good fit. ${ }^{34,35}$ SPSS (version 18.0; SPSS Inc, Chicago, Illinois) was used for the descriptive statistics, and IBM SPSS AmosV22 statistical software was used for the SEM. ${ }^{36}$

\section{Results}

\section{PEARSON'S CORRELATIONS}

Table 3 shows the means (Ms), SDs, and Pearson's correlation matrix for the constructs of the ASSISTS model. The correlations between the measures were in the expected direction. Moderate positive associations were found between all constructs.

\section{MODEL TESTING AND MODEL FIT}

The measurement model provided a good fit, $\chi^{2} / d f=1.86$, RMSEA $=0.031$ (90\% confidence interval: $0.021-0.089)$, and $S R M R=0.03$, which was lower than 0.08 , thus indicating a good fit of the model. The GFI, adjusted goodness of fit index, CFI, NNFI, and NFI were higher than $0.90(0.99,0.98$, 0.94, 1, and 0.98, respectively). Furthermore, the Cronbach's $\alpha$ coefficient for the instrument revealed good internal consistency $(\alpha=.79)$, and the intraclass correlation coefficient of the ASSISTS scale was satisfactory (intraclass correlation coefficient $=0.086$ ). Furthermore, the model (Figure 2) provided a good fit to the data $\left(\chi^{2}=0.211, P=.646\right.$, RMSEA $=.00, \mathrm{NFI}=1.00, \mathrm{NNFI}=0.99$, 
Table $3^{\bullet}$ Means, SDs, and Pearson's Correlation Coefficients of Variables Used in the SEM $(\mathrm{N}=260)$

\begin{tabular}{|c|c|c|c|c|c|c|c|c|c|}
\hline Construct & M & SD & Attitude & Motivation & Self-efficacy & $\begin{array}{c}\text { Information } \\
\text { Seeking }\end{array}$ & $\begin{array}{c}\text { Stress } \\
\text { Management }\end{array}$ & Self-care & $\begin{array}{l}\text { Social } \\
\text { Support }\end{array}$ \\
\hline Attitude & 28.26 & 6.39 & 1.00 & & & & & & \\
\hline Motivation & 11.85 & 2.66 & $0.709^{\mathrm{a}}$ & 1.00 & & & & & \\
\hline Self-efficacy & 12.09 & 2.44 & $0.687^{\mathrm{a}}$ & $0.781^{\mathrm{a}}$ & 1.00 & & & & \\
\hline Information seeking & 14.54 & 3.41 & $0.762^{\mathrm{a}}$ & $0.648^{\mathrm{a}}$ & $0.704^{\mathrm{a}}$ & 1.00 & & & \\
\hline Stress management & 11.01 & 2.79 & $0.724^{\mathrm{a}}$ & $0.784^{\mathrm{a}}$ & $0.751^{\mathrm{a}}$ & $0.651^{\mathrm{a}}$ & 1.00 & & \\
\hline Self-care & 25.54 & 5.70 & $0.801^{\mathrm{a}}$ & $0.772^{\mathrm{a}}$ & $0.824^{\mathrm{a}}$ & $0.719^{\mathrm{a}}$ & $0.736^{\mathrm{a}}$ & 1.00 & \\
\hline Social support & 17.45 & 4.12 & $0.654^{\mathrm{a}}$ & $0.626^{\mathrm{a}}$ & $0.659^{\mathrm{a}}$ & $0.643^{\mathrm{a}}$ & $0.670^{\mathrm{a}}$ & $0.717^{\mathrm{a}}$ & 1.00 \\
\hline
\end{tabular}

${ }^{\mathrm{a}} P<.01$.

$\mathrm{CFI}=1.00, \mathrm{TLI}=1.00, \mathrm{SRMR}=0.067, \mathrm{GFI}=1.00$, and adjusted goodness of fit index $=0.993$ ).

Table 4 displays the standardized regression coefficients of the relations between the constructs of our conceptual model. Our conceptual model was confirmed, with significant positive associations between perceived social support and self-efficacy, motivation, and attitude, which in turn were positively associated with information seeking, self-care, and stress management. Furthermore, social support was positively associated with information seeking, self-care, and stress management, and information seeking was positively associated with self-care and stress management.

\section{Discussion}

Breast cancer is one of the most frequent cancers in women, especially those living in developing countries. A huge increase in breast cancer incidence worldwide has been highlighted, and the most quickly growing part is that of women younger than 40 years. ${ }^{1}$ Therefore, using different procedures and expanding new interventions to improve sufferers' well-being and reduce the risk of breast cancer are of major importance. To the best of our knowledge, no study has developed and implemented such a model with regard to breast cancer prevention. In the present study, we described the development and assessment of an educational model, called the ASSISTS, that aims to improve breast cancerpreventive behaviors in Iranian women, as well as in other women.

The present study contributes to the literature by applying a holistic viewpoint to promoting women's breast cancer-preventive behaviors. Our conceptual model was based on a secondary analysis of previous qualitative data to identify factors affecting breast cancer-preventive behaviors in women. ${ }^{18}$ The secondary analyses revealed that breast cancer-preventive behaviors comprised 7 constructs, including social support, attitude, motivation, self-efficacy, information seeking, stress management, and self-care. Based on the literature, we then examined the associations between the 7 constructs, which had never been documented before. By using advanced statistical analyses, the present study allowed for a more complex testing of the associations and the influences between the constructs. In particular, this study pointed out more specific information on constructs involved in interventions that enhance breast cancer-preventive behaviors and, consequently, women's health.

The 7 constructs in the present study have some similarities with the constructs of the high-level wellness lifestyle described by Ardell. ${ }^{37}$ For instance, the stress-management construct of Ardell's 5 dimensions of a wellness lifestyle shows similarities with the stress-management construct identified in the present

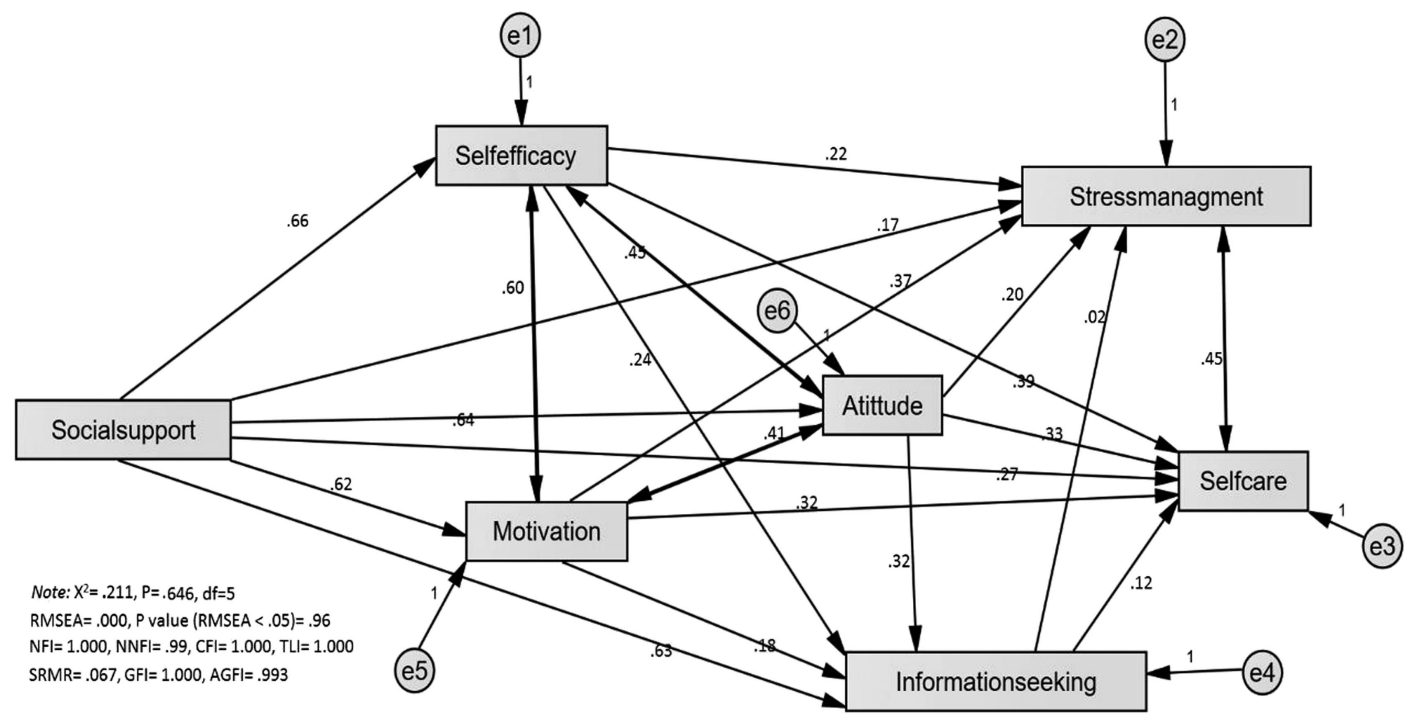

Figure 2 Final SEM with standardized regression coefficients. 
Table $4^{\bullet}$ Standardized Regression Coefficients for ASSISTS Model

\begin{tabular}{|c|c|c|c|c|c|c|}
\hline SEM Model & & & Estimate & SE & CR & $P$ \\
\hline Self-efficacy & $\leftarrow$ & Social support & 0.658 & 0.028 & 14.075 & $<.001$ \\
\hline Motivation & $\leftarrow$ & Social support & 0.626 & 0.031 & 12.904 & $<.001$ \\
\hline Attitude & $\leftarrow$ & Social support & 0.642 & 0.068 & 13.462 & $<.001$ \\
\hline Information seeking & $\leftarrow$ & Social support & 0.624 & 0.038 & 12.837 & $<.001$ \\
\hline Stress management & $\leftarrow$ & Social support & 0.170 & 0.033 & 3.492 & $<.001$ \\
\hline Self-care & $\leftarrow$ & Social support & 0.266 & 0.055 & 4.160 & $<.001$ \\
\hline Information seeking & $\leftarrow$ & Attitude & 0.324 & 0.035 & 6.429 & $<.001$ \\
\hline Stress management & $\leftarrow$ & Attitude & 0.201 & 0.027 & 3.553 & $<.001$ \\
\hline Self-care & $\leftarrow$ & Attitude & 0.333 & 0.045 & 7.210 & $<.001$ \\
\hline Information seeking & $\leftarrow$ & Self-efficacy & 0.242 & 0.024 & 4.015 & $<.001$ \\
\hline Stress management & $\leftarrow$ & Self-efficacy & 0.222 & 0.069 & 3.656 & $<.001$ \\
\hline Self-care & $\leftarrow$ & Self-efficacy & 0.387 & 0.016 & 7.799 & $<.001$ \\
\hline Information seeking & $\leftarrow$ & Motivation & 0.178 & 0.023 & 3.948 & .004 \\
\hline Stress management & $\leftarrow$ & Motivation & 0.374 & 0.061 & 6.403 & $<.001$ \\
\hline Self-care & $\leftarrow$ & Motivation & 0.318 & 0.002 & 2.902 & .004 \\
\hline Stress management & $\leftarrow$ & Information seeking & 0.024 & 0.048 & 0.266 & .008 \\
\hline Self-care & $\leftrightarrow$ & Information seeking & 0.116 & 0.079 & 0.143 & .002 \\
\hline Motivation & $\leftrightarrow$ & Attitude & 0.417 & 0.032 & 5.810 & $<.001$ \\
\hline Self-efficacy & $\leftrightarrow$ & Attitude & 0.451 & 0.032 & 5.408 & $<.001$ \\
\hline Motivation & $\leftrightarrow$ & Self-efficacy & 0.595 & 0.057 & 10.621 & $<.001$ \\
\hline Stress management & $\leftrightarrow$ & Self-care & 0.447 & 0.063 & 3.059 & $<.001$ \\
\hline
\end{tabular}

Abbreviation: CR, critical ratio.

study. In addition, 3 of Ardell's 5 constructs of a wellness lifestyle (ie, self-responsibility, nutritional awareness, and physical fitness) are similar in meaning to the self-care construct that was identified in the current study. ${ }^{38}$

Based on our conceptual model, we found that self-care behavior and stress management are influenced directly by attitude, motivation, self-efficacy, information seeking, and social support. Our findings also suggest that women seek more information when they are motivated, have more self-efficacy, have a more positive attitude toward breast cancer prevention, and experience more social support. The desire and ability to take part in preventive behaviors may be most relevant when women believe that they are at high risk for breast cancer and that selfcare behaviors may have protective benefits. In a way, our research findings are also consistent with Eagly and Chaiken's ${ }^{38}$ multiple attitude-behavior model, which is specifically attractive due to its generality. Based on Eagly and Chaiken's ${ }^{38}$ model, behavior is partly adjusted with attitudes by applying attitudes along with other factors, such as intentions, perceived useful outcomes, and habits, that also help to determine behavior. Salehi and colleagues ${ }^{39}$ found that that the level of perceived control and self-efficacy could be an effective means in participants' activity for a healthy lifestyle and well-being.

Our findings also confirmed positive associations between social support and all other constructs of the model. Social support not only directly relates to self-care and stress management but also indirectly influences self-care behavior and stress management by its association with attitude, motivation, self-efficacy, and information seeking. The core of social support refers to the person's perception that others will give impressive assistance during times of need. ${ }^{40}$ It seems that more effective support from different sources may lead to higher levels of preventive behaviors in women by encouraging them to use more stress-management methods and self-care behaviors through having a positive attitude, maintaining good self-efficacy, and seeking more information regarding breast cancer prevention, and in turn, these women may be more likely to have better preventive behaviors. Previous studies have highlighted that social support is related to the promotion of psychological and physical well-being, such as reducing high stress levels in cancer patients $^{28}$ and decreasing death risk in chronic disease populations. ${ }^{41}$ In addition, social support has been associated with a healthy lifestyle, ${ }^{19}$ self-efficacy, ${ }^{26}$ information-seeking behavior, ${ }^{42}$ and motivation. ${ }^{43}$

Our model showed that motivation and information-seeking behavior are significantly associated with self-care behaviors and stress management. Vancampfort ${ }^{44}$ also reported that motivation is the key to effectively applying lifestyle modifications in illnesses. In Kähkönen's ${ }^{45}$ study, motivation was found to be an essential factor in a healthy lifestyle among persons with coronary heart disease after intervention. Furthermore, information seeking is progressively recognized as a key approach in women's health-preventive activities regarding breast cancer. For women, believing that they have a chance of getting breast cancer may motivate them to search for information about lifestyle behaviors that may help to maintain their health and decrease their risk of developing breast cancer. This is consistent with a study conducted by Ramirez and colleagues, ${ }^{46}$ which found that the effects of seeking healthy information from media and friends/family were dependent on healthy lifestyle behaviors such as healthy eating and physical exercise. Although correct information is an important source for supporting women and families to explain the meaning of preventive behaviors, more studies may be required to explain 
how it helps to decrease women's doubts and negative attitudes about breast cancer prevention in Iran. Given the current findings and an extended focus on women's responsibility for their well-being, this may be particularly true for women who want more information about breast cancer prevention beyond what they get from their healthcare provider. Interacting with somebody who can provide health information may noticeably help Iranian women to decrease their uncertainty about breast cancer prevention.

The results of the present study might help cancer nurses who care for critically ill cancer patients. Cancer nurses are a valuable source for patients because they create a supportive environment by helping patients with the challenges and difficulties involved in early detection. ${ }^{47}$ Cancer nurses can help patients by educating them about treatment options, and they can also help by educating people about screening behaviors to prevent cancer. Knowledge about the associations between the 7 themes of the ASSISTS might help cancer nurses to increase the awareness of women about cancer-preventive behaviors. ${ }^{48}$ When women are aware of the importance of preventive behaviors, they will have greater motivation to perform such behaviors. $^{31}$

\section{- Strengths and Limitations}

A strength of this study is that we used qualitative data in developing an educational model and thereafter examined empirically the associations between social support, attitude, motivation, self-efficacy, information seeking, stress management, and self-care.

Nevertheless, the present study also had some limitations. One important limitation is that this study was conducted in only 1 city of Iran (ie, the capital of Iran), one of the world's developing countries. It is hard to identify how applicable these results may be to people of other countries, and thus, the study may have limited external validity. Therefore, it might be interesting to repeat the study with women from different cultural backgrounds living in other cities/countries. A second limitation concerns the use of self-reported information, which involves a certain risk that the results are based on common-method variance. ${ }^{49}$ The present study supposed that the self-reported information was a genuine reflections of the women's activities. Furthermore, the fact that the researchers met the women to assist with filling in the questionnaire might have introduced some bias into the report. To reduce this bias, skilled researchers were recruited to conduct the research. A final limitation is that our data are cross-sectional. Based on the literature, we have assumed several associations between the constructs, but we acknowledge that reciprocal causation or bidirectionality between the constructs cannot be ruled out.

\section{- Conclusion}

This study reported the development and investigation of an educational model for promoting women's behaviors to prevent breast cancer. Based on a secondary analysis of a previous qualitative study, 7 constructs were discerned, including perceived social support, attitude, motivation, self-efficacy, information seeking, stress management, and self-care. Our results indicate that self-care behavior and stress management are influenced directly by attitude, motivation, self-efficacy, information seeking, and social support. Cancer nurses can be at the forefront of breast cancer prevention. Because they can play a pivotal role in providing information, they can reduce women's stress and increase their self-care behavior. Furthermore, by providing social support, they can positively influence Iranian women's attitude, motivation, and self-care behavior. The results of the present study may also help investigators who desire to describe the breast cancerpreventive behavior components in different populations and who want to effectively plan preventive health-related behavioral approaches for women. Further research involving other samples with different socioeconomic levels and cultural backgrounds is, however, required to better explain the constructs of our model.

\section{ACKNOWLEDGMENTS}

We would like to thank all participants for their activity in this study and the experts involved; without their support, this study would not have been possible. The authors are also thankful for help received from the Department of Health Education \& Promotion, School of Health, Tehran University of Medical Sciences.

\section{References}

1. Baselga J, Bhardwaj N, Cantley LC, et al. AACR Cancer Progress Report 2015. Clin Cancer Res. 2015;21(19 suppl):S1-S128.

2. Ferlay J, Soerjomataram I, Dikshit R, et al. Cancer incidence and mortality worldwide: sources, methods and major patterns in GLOBOCAN 2012. Int J Cancer. 2015;136(5):E359-E386.

3. Akinyemiju TF. Socio-economic and health access determinants of breast and cervical cancer screening in low-income countries: analysis of the World Health Survey. PLoS One. 2012;7(11):e48834.

4. Bosetti C, Bertuccio P, Malvezzi M, et al. Cancer mortality in Europe, 2005-2009, and an overview of trends since 1980. Ann Oncol. 2013;24(10): $2657-2671$.

5. Abdoli G, Bottai M, Sandelin K, Moradi T. Breast cancer diagnosis and mortality by tumor stage and migration background in a nationwide cohort study in Sweden. Breast. 2017;31:57-65.

6. Montazeri A, Vahdaninia M, Harirchi I, et al. Breast cancer in Iran: need for greater women awareness of warning signs and effective screening methods. Asia Pac Fam Med. 2008;7(1):1.

7. Jazayeri SB, Saadat S, Ramezani R, Kaviani A. Incidence of primary breast cancer in Iran: ten-year national cancer registry data report. Cancer Epidemiol. 2015;39(4):519-527.

8. Mizoo T, Taira N, Nishiyama K, et al. Effects of lifestyle and single nucleotide polymorphisms on breast cancer risk: a case-control study in Japanese women. BMC Cancer. 2013;13:565.

9. Wang L, Liao WC, Tsai CJ, et al. The effects of perceived stress and life style leading to breast cancer. Women Health. 2013;53(1):20-40.

10. McLeish L, Reis MM, Stewart C, et al. Lifestyle changes in women at genetic risk of breast cancer: an observational study. Int J Behav Med. 2013;20(4):514-521.

11. Khazaee-Pool M, Majlessi F, Foroushani AR, Montazeri A, Nedjat S, Shojaeizadeh D. Perception of breast cancer screening among Iranian women without experience of mammography: a qualitative study. Asian Pac J Cancer Prev. 2014;15:3965-3971. 
12. Abraham C, Kelly MP, West R, Michie S. The UK National Institute for Health and Clinical Excellence public health guidance on behaviour change: a brief introduction. Psychol Health Med. 2009;14(1):1-8.

13. Ahmadian M, Samah AA. Application of health behavior theories to breast cancer screening among Asian women. Asian Pac J Cancer Prev. 2013; 14(7):4005-4013.

14. Torbaghan AE, Farmanfarma KK, Moghaddam AA, Zarei Z. Improving breast cancer preventive behavior among female medical staff: the use of educational intervention based on health belief model. Malays J Med Sci. 2014;21(5):44-50.

15. Hajian-Tilaki K, Auladi S. Health belief model and practice of breast self-examination and breast cancer screening in Iranian women. Breast Cancer. 2014;21(4):429-434.

16. Kadivar M, Joolaee S, Joulaee A, Bahrani N, Hosseini N. Breast cancer knowledge, attitudes and screening behaviors in two groups of Iranian women: physicians and non-health care personnel. J Cancer Educ. 2012;27(4): 770-773.

17. Aghamolaei T, Hasani L, Tavafian SS, Zare S. Improving breast selfexamination: an educational intervention based on health belief model. Iran J Cancer Prev. 2011;4(2):82-87.

18. Khazaee-Pool M, Montazeri A, Majlessi F, Rahimi Foroushani A, Nedjat S, Shojaeizadeh D. Breast cancer-preventive behaviors: exploring Iranian women's experiences. BMC Womens Health. 2014;14(1):41.

19. Alcañiz M, Brugulat $P$, Guillén M, Medina-Bustos A, Mompart-Penina A, Solé-Auró A. Risk of dependence associated with health, social support, and lifestyle. Rev Saude Publica. 2015;49:26.

20. Pascoe JM, Loda FA, Jeffries V, Earp JA. The association between mothers' social support and provision of stimulation to their children. J Dev Behav Pediatr. 1981;2(1):15-19.

21. Brouwer S, Reneman MF, Bültmann U, Van der Klink JJ, Groothoff JW. A prospective study of return to work across health conditions: perceived work attitude, self-efficacy and perceived social support. J Occup Rehabil. 2010;20(1):104-112.

22. Jensen LF, Pedersen AF, Andersen B, Vedsted P. Self-assessed health, perceived stress and non-participation in breast cancer screening: a Danish cohort study. Prev Med. 2015;81:392-398.

23. Jansen F, van Uden-Kraan CF, van Zwieten V, Witte BI, Verdonck-de Leeuw IM. Cancer survivors' perceived need for supportive care and their attitude towards self-management and eHealth. Support Care Cancer. 2015; 23(6):1679-1688.

24. Kamimura A, Tabler J, Nourian MM, et al. Promoting healthy eating attitudes among uninsured primary care patients. J Community Health. 2016;41(4):805-811.

25. Kanera IM, Bolman CA, Mesters I, Willems RA, Beaulen A, Lechner L. Prevalence and correlates of healthy lifestyle behaviors among early cancer survivors. BMC Cancer. 2016;16:4.

26. Lotfi-Kashani F, Vaziri S, Akbari ME, Kazemi-Zanjani N, Shamkoeyan L. Predicting post traumatic growth based upon self-efficacy and perceived social support in cancer patients. Iran J Cancer Prev. 2014;7(3):115.

27. Chen SY, Wang HH. The relationship between physical function, knowledge of disease, social support and self-care behavior in patients with rheumatoid arthritis. J Nurs Res. 2007;15(3):183-192.

28. McDonough MH, Sabiston CM, Wrosch C. Predicting changes in posttraumatic growth and subjective well-being among breast cancer survivors: the role of social support and stress. Psychooncology. 2014;23(1):114-120.

29. Keinki C, Seilacher E, Ebel M, et al. Information needs of cancer patients and perception of impact of the disease, of self-efficacy, and locus of control. J Cancer Educ. 2015:1-7.
30. Kimiafar K, Sarbaz M, Shahid Sales S, Esmaeili M, Javame Ghazvini Z. Breast cancer patients' information needs and information-seeking behavior in a developing country. Breast. 2016;28:156-160.

31. Khazaee-Pool M, Majlessi F, Montazaeri A, Pashaei T, Gholami A, Ponnet K. Development and psychometric testing of a new instrument to measure factors influencing women's breast cancer prevention behaviors (ASSISTS). BMC Womens Health. 2016;16:40.

32. Jöreskog KG, Sörbom D, Du Toit S. LISREL 8: NEW STATISTICAL FEATURES: Scientific Software International; 2001.

33. Hu Lt, Bentler PM. Fit indices in covariance structure modeling: sensitivity to underparameterized model misspecification. Psychol Methods. 1998;3(4):424.

34. MacCallum RC, Austin JT. Applications of structural equation modeling in psychological research. Annu Rev Psychol. 2000;51(1):201-226.

35. Kline RB. Measurement models and confirmatory factor analysis. In: Principles and Practice of Structural Equation Modeling. New York: Guilford Press; 2005.

36. Arbuckle JL. IBM SPSS AMOS 22 User's Guide. Chicago, IL: SPSS Inc; 2009.

37. Ardell $\mathrm{D}$. The nature and implications of high level wellness, or why "normal health" is a rather sorry state of existence. Health Values. 1979;3(1):17-24.

38. Eagly AH, Chaiken S. The Psychology Of Attitudes. 1st ed. Florida: Harcourt Brace Jovanovich College Publishers; 1993.

39. Salehi A, Harris N, Coyne E, Sebar B. Perceived control and self-efficacy, subjective well-being and lifestyle behaviours in young Iranian women. $J$ Health Psychol. 2016;21(7):1415-1425.

40. Documet P, Bear TM, Flatt JD, Macia L, Trauth J, Ricci EM. The association of social support and education with breast and cervical cancer screening. Health Educ Behav. 2015;42(1):55-64.

41. Yilmaz SD, Bal MD, Beji NK, Arvas M. Ways of coping with stress and perceived social support in gynecologic cancer patients. Cancer Nurs. 2015; 38(2):E57-E62.

42. Kim W, Kreps GL, Shin CN. The role of social support and social networks in health information-seeking behavior among Korean Americans: a qualitative study. Int J Equity Health. 2015;14:40.

43. Fernández BR, Warner LM, Knoll N, Montenegro EM, Schwarzer R. Synergistic effects of social support and self-efficacy on dietary motivation predicting fruit and vegetable intake. Appetite. 2015;87:330-335.

44. Vancampfort D, Madou T, Moens H, et al. Could autonomous motivation hold the key to successfully implementing lifestyle changes in affective disorders? A multicentre cross sectional study. Psychiatry Res. 2015;228(1): 100-106.

45. Kähkönen O, Kankkunen P, Saaranen T, Miettinen H, Kyngäs H, Lamidi ML. Motivation is a crucial factor for adherence to a healthy lifestyle among people with coronary heart disease after percutaneous coronary intervention. J Adv Nurs. 2015;71(10):2364-2373.

46. Ramírez AS, Freres D, Martinez LS, et al. Information seeking from media and family/friends increases the likelihood of engaging in healthy lifestyle behaviors. J Health Commun. 2013;18(5):527-542.

47. Leeman J, Moore A, Teal R, Barrett N, Leighton A, Steckler A. Promoting community practitioners' use of evidence-based approaches to increase breast cancer screening. Public Health Nurs. 2013;30(4):323-331.

48. Murphy JL, Girot EA. The importance of nutrition, diet and lifestyle advice for cancer survivors the role of nursing staff and interprofessional workers. J Clin Nurs. 2013;22(11-12):1539-1549.

49. Podsakoff PM, MacKenzie SB, Lee JY, Podsakoff NP. Common method biases in behavioral research: a critical review of the literature and recommended remedies. Journal of applied psychology. 2003;88(5):879. 